\title{
Correlates of tobacco product initiation among youth and adults in the USA: findings from the PATH Study Waves 1-3 (2013-2016)
}

\author{
Karin A Kasza (1) ,' Kathryn C Edwards 다, ${ }^{2}$ Zhiqun Tang, ${ }^{2}$ \\ Cassandra A Stanton (1), 2,3 Eva Sharma (1) , ${ }^{2}$ Michael J Halenar (1), ${ }^{2}$ \\ Kristie A Taylor (10, ${ }^{2}$ Elisabeth A Donaldson, ${ }^{4}$ Lynn C Hull, ${ }^{4}$ Hannah Day, ${ }^{4}$ \\ Maansi Bansal-Travers (1) , ${ }^{1}$ Jean Limpert, ${ }^{4}$ Izabella Zandberg, ${ }_{1}^{4}$ Lisa D Gardner (1) , ${ }^{4}$ \\ Hoda T Hammad, ${ }^{4}$ Nicolette Borek, ${ }^{4}$ Heather L Kimmel $10,{ }^{5}$ Wilson M Compton, ${ }^{5}$ \\ Andrew Hyland ${ }^{1}$
}

- Additional material is published online only. To view, please visit the journal online (http://dx.doi.org/10.1136/ tobaccocontrol-2020-055671)

'Department of Health Behavior, Roswell Park Comprehensive Cancer Center, Buffalo, NY, USA ${ }^{2}$ Behavioral Health and Health Policy Practice, Westat, Rockville MD, USA

${ }^{3}$ Department of Oncology, Georgetown University Medical Center, Washington, DC, USA ${ }^{4}$ Office of Science, Center for Tobacco Products, Food and Drug Administration, Silver Spring, MD, USA

${ }^{5}$ National Institute on Drug Abuse, National Institutes of Health, Bethesda, MD, USA

Correspondence to

Dr Karin A Kasza, Department of Health Behavior, Roswell Park Comprehensive Cancer Center, Buffalo, NY 14263, USA; karin.kasza@roswellpark.org

Received 31 January 2020 Revised 6 February 2020 Accepted 7 February 2020

Check for updates

(C) Author(s) (or their employer(s)) 2020. No commercial re-use. See rights and permissions. Published by BMJ.

To cite: Kasza KA

Edwards KC, Tang Z, et al.

Tob Control

2020;29:s191-s202.

\section{ABSTRACT}

Objective To report on demographic and tobacco product use correlates of tobacco product initiation (cigarettes, electronic nicotine delivery systems (ENDS), cigars, hookah and smokeless tobacco) among the US population.

Design Data were from the first three waves (20132016) of the Population Assessment of Tobacco and Health Study, a nationally representative, longitudinal cohort study of US youth (aged 12-17 years) and adults (aged $18+$ years). Never users of at least one type of tobacco product at Wave 1 (W1, 2013/14) or Wave 2 (W2, 2014/15) were included ( $n=12987$ youth; $n=25116$ adults). Generalised estimating equations were used to evaluate the association between demographic and tobacco product use characteristics at baseline, and tobacco product initiation at follow-up (ever, past 30 day (P30D), frequent (use on 20 or more of thepast 30 days)) over two 1-year periods (W1-W2 and W2-Wave 3).

Results Youth aged 15-17 years were more likely than youth aged 12-14 years and adults aged 18-24 years were more likely than older adults to initiate P30D tobacco use across products; non-heterosexuals were more likely than heterosexuals to initiate P30D cigarette and ENDS use. Older adults were more likely than young adults, and males were more likely than females, to be frequent users of ENDS on initiation. Ever use of another tobacco product predicted P30D initiation of each tobacco product.

Discussion Other tobacco product use and age predict P30D tobacco initiation across products whereas associations with other demographic characteristics vary by product. Continued contemporary evaluation of initiation rates within the changing tobacco product marketplace is important.

\section{INTRODUCTION}

Reducing tobacco initiation is one of a triad of strategies-along with increasing cessation among current tobacco users and reducing relapse among former tobacco users-that will improve population health. ${ }^{1}$ It is well-established that most cigarette smoking initiation occurs by age 18 and nearly all adult cigarette smokers (99\%) smoke their first cigarette by age $26 .^{2}$ In 2013-16, past 30-day (P30D) initiation rates were highest among young adults (aged 18-24 years) followed by youth (aged 12-17 years) for cigarettes, hookah and cigars, and were similar between youth and young adults for electronic nicotine delivery systems (ENDS). Understanding correlates of ever, P30D and frequent use initiation across tobacco products can help in targeting prevention efforts and can enable researchers to make better population-level predictions of the potential impacts of regulatory actions and other public health efforts.

Demographic characteristics associated with tobacco product initiation rates are often inferred by cross-sectional data that report on characteristics of tobacco product users at a single point in time (prevalence). Males, those who are not heterosexual, and those of low socioeconomic status generally have higher tobacco use prevalence than their counterparts. ${ }^{4-10}$ However, correlates of use sometimes differ by tobacco product type. For example, adults with higher household income tend to have lower prevalence of cigarette use but higher prevalence of traditional cigar use compared with those with lower incomes. Those who are nonHispanic white tend to have lower prevalence of cigarette use but higher prevalence of ENDS use compared with those who are non-Hispanic black.

The role that one type of tobacco product may play in initiation of another type of tobacco product is an important consideration as the scope of tobacco products available to consumers has expanded and concurrent use of multiple tobacco products has become common among tobacco users in the USA. ${ }^{411} 12$ Among youth and young adults, use of ENDS has been found to predict ever cigarette initiation, ${ }^{13-17}$ with one study also finding that ENDS use predicts P30D cigarette initiation. ${ }^{18}$ Evaluating the transition to $\mathrm{P} 30 \mathrm{D}$ use or frequent use focuses on initiation rates more likely to contribute to subsequent nicotine addiction and health effects if maintained. ${ }^{19}$

The purpose of this paper is to report on demographic and tobacco product use correlates of ever, P30D and frequent tobacco product use initiation across types of tobacco products (cigarettes, ENDS, cigars, hookah and smokeless tobacco), 
among the US population of youth (aged 12-17 years) and adults (aged 18+ years) using data from Waves 1, 2 and 3 (W1, W2 and W3, respectively) of the Population Assessment of Tobacco and Health (PATH) Study.

\section{METHODS}

\section{Data source and participants}

The PATH Study is an ongoing, nationally representative, longitudinal cohort study of youth and adults in the USA. Data were collected from September 2013 to December 2014 (W1); October 2014 to October 2015 (W2) and October 2015 to October 2016 (W3) using audio computer-assisted self-interviews administered in English or Spanish. The overall weighted response rate was $78.4 \%$ for youth and $74.0 \%$ for adults at W1, $87.3 \%$ for youth and $83.2 \%$ for adults at W2 and $83.3 \%$ for youth and $78.4 \%$ for adults at W3. Further details regarding the PATH Study design and $\mathrm{W} 1$ methods are published elsewhere. ${ }^{20}$ Details on interviewing procedures, questionnaires, sampling, weighting, response rates and accessing the data are described in the PATH Study Restricted Use Files User Guide at https://doi.org/10.3886/ Series606. ${ }^{21}$ The study was conducted by Westat and approved by the Westat Institutional Review Board. All respondents ages 18 and older provided informed consent, with youth respondents ages 12 to 17 providing assent and each youth's parent/ legal guardian providing consent. All respondents ages 18 or older provided informed consent, with youth respondents ages 12-17 providing assent while each one's parent/legal guardian provided consent. Data in this paper were drawn from respondents in W1, W2 and W3 of the PATH Study, which includes 25384 adults at W1 or W2, and 12993 youth at W1 or W2. See online supplementary table 1 for additional details.

This paper describes correlates of tobacco product initiation over two 1-year periods in a single analysis, so the analytic sample was restricted to respondents who never used at least one type of tobacco product at W1 or W2, which includes 24432 adults and 12938 youth. W1 and W2 are each considered the 'baseline' wave to the subsequent wave, such that W1 is the baseline to W2, and W2 is the baseline to W3. Inclusion in the youth analyses versus the adult analyses was determined based on age at baseline wave. (That is, youth never users who aged into the adult cohort at W2 were included in the youth analyses between W1 and W2 $(\mathrm{N}=1687)$ and in the adult analyses between $\mathrm{W} 2$ and W3 (N=1669). 'Shadow youth', who aged into the youth cohort at W2 and were youth never users at W2 $(\mathrm{N}=1946)$, were included in the youth analyses between W2 and W3.) The weighted estimates presented in this paper represent the resident non-incarcerated population of the USA at the time of W3 who were in the civilian, non-institutionalised population aged 9 years and older at W1, through application of population and replicate weights that adjust for complex study design characteristics and non-response at W1, W2 and W3.

\section{Measures}

Tobacco product use

Tobacco products were grouped into five types: cigarettes, ENDS (e-cigarettes at W1 and e-cigarettes, e-cigars, e-pipes and e-hookah at W2 and W3), cigars (traditional cigars, cigarillos and filtered cigars), hookah and smokeless tobacco (loose snus, moist snuff, dip, spit, chewing tobacco and snus pouches). For each of these five types of tobacco products and for any tobacco product, tobacco use statuses-never use, ever use, P30D use and frequent use (smoked/used the product on 20 or more of the past 30 days, consistent with the reporting of 'frequent use' for cigarettes by the US Centers for Disease Control and Prevention along with that of various other publications, ${ }^{422}{ }^{23}$-were assessed at each wave, defined in table 1.

\section{Outcomes}

The following thresholds of initiation were assessed at follow-up, as defined in table 1: (1) initiating ever use (ie, never product user at baseline and ever product user at follow-up), (2) initiating P30D use (ie, never product user at baseline and P30D product user at follow-up) and (3) initiating frequent use among those who initiated P30D use (ie, never product user at baseline who initiated P30D use at follow-up and used the product on 20 or more of the past 30 days at follow-up).

\section{Demographic characteristics}

Demographic characteristics were assessed at the baseline wave and categorised as shown in the tables. Missing data on age, sex, race and Hispanic ethnicity were imputed at $\mathrm{W} 1$ as described in the PATH Study Restricted Use Files User Guide at https://doi. org/10.3886/Series606. ${ }^{24}$ (Imputed sex and race/ethnicity were carried forward to also represent these characteristics at W2; however, age at W2 was used since the time between interviews may not have yielded one additional year in all instances.)

\section{Statistical analyses}

For each type of tobacco product, generalised estimating equations (GEE) were used to evaluate the association between correlates assessed at baseline and initiation assessed at follow-up, over two 1-year periods (W1-W2 and W2-W3). This statistical method allows for the inclusion of transitions from both periods in a single analysis while statistically controlling for interdependence among observations contributed by the same individuals. ${ }^{25} 26$ Specifically, GEE logistic regression models specified unstructured covariance and within-person correlation matrices and the

\begin{tabular}{|c|c|c|}
\hline Initiation behaviours & Baseline tobacco use group (W1 or W2) & Follow-up outcome (W2 or W3) \\
\hline $\begin{array}{l}\text { Initiating ever use } \\
\text { (online supplementary tables } 2 \text { and } 3 \text { ) }\end{array}$ & $\begin{array}{l}\text { Never users*: never smoked/used the product/any } \\
\text { tobacco product (even one or two times) }\end{array}$ & $\begin{array}{l}\text { Initiating ever use: ever smoked/used the product/any } \\
\text { tobacco product (even one or two times) }\end{array}$ \\
\hline $\begin{array}{l}\text { Initiating P30D use } \\
\text { (tables } 2 \text { and } 3 \text { ) }\end{array}$ & Never users as defined above & $\begin{array}{l}\text { Initiating P30D use: smoked/used the product/any tobacco } \\
\text { product in the P30D }\end{array}$ \\
\hline $\begin{array}{l}\text { Initiating frequent use among those who initiated P30D } \\
\text { use } \\
\text { (results in-text only) }\end{array}$ & $\begin{array}{l}\text { Never users who initiated P30D use at follow-up as } \\
\text { defined above }\end{array}$ & $\begin{array}{l}\text { Frequent use on initiationt: smoked/used the product on } \\
20 \text { or more of the past } 30 \text { days }\end{array}$ \\
\hline
\end{tabular}


binomial distribution of the dependent variable using the logit link function. Analyses were weighted using the W3 'all-waves' weights to produce nationally representative estimates, and variances were computed using the balanced repeated replication method $^{27}$ with Fay's adjustment set to $0.3 .^{28}$ All analyses were conducted using SAS V.9.4 software (SAS Institute, Cary, North Carolina, USA). See online supplementary material for the SAS macro code used to run weighted GEE analyses and calculate adjusted ORs (aORs) and CIs. Analyses were run on the W1-W3 Restricted Use Files (https://doi.org/10.3886/ICPSR36231.v18).

For each type of tobacco product, initiation was evaluated with respect to the given tobacco product. Demographic correlates, never/ever tobacco use correlates and wave were included in each model. All analyses were conducted among adults and youth (defined at baseline) separately. For the youth analyses, separate models were run to evaluate sexual orientation because only youth aged 14-17 years were asked about sexual orientation. Estimates with a relative standard error $>30$ or with a denominator $<50$ are suppressed since these estimates may provide unreliable precision and to protect respondent confidentiality.

\section{RESULTS}

\section{Ever tobacco product use initiation}

Correlates of ever tobacco product use initiation are reported among youth in online supplementary table 2 and among adults in online supplementary table 3 . Given the similarity in significant correlates of ever use initiation and P30D initiation, we focus on P30D initiation here in text.

\section{P30D initiation}

\section{Youth}

\section{Any tobacco product}

Among youth, older age $(\mathrm{aOR}=3.2,95 \% \mathrm{CI}: 2.6$ to 3.8$)$ and not identifying as heterosexual/straight $(\mathrm{aOR}=1.6,95 \% \mathrm{CI}$ : 1.2 to 2.2) were associated with higher odds of initiating P30D use of any tobacco product compared with younger age and identifying as heterosexual/straight, respectively. Non-Hispanic black ( $\mathrm{aOR}=0.7,95 \% \mathrm{CI}: 0.5$ to 0.9$)$ and nonHispanic other $(\mathrm{aOR}=0.6,95 \% \mathrm{CI}$ : 0.4 to 0.8$)$ race/ethnicity were each associated with lower odds of initiating P30D use than non-Hispanic white race/ethnicity (table 2 ).

\section{Cigarettes}

Among youth, older age $(\mathrm{aOR}=2.4,95 \% \mathrm{CI}: 1.8$ to 3.3$)$, not identifying as heterosexual/straight $(\mathrm{aOR}=1.9,95 \% \mathrm{CI}: 1.3$ to 2.9 ) and ever use of ENDS (aOR=3.4, 95\% CI: 2.4 to 4.7 ), cigars $(\mathrm{aOR}=2.0,95 \% \mathrm{CI}: 1.1$ to 3.7$)$, hookah $(\mathrm{aOR}=2.2$, 95\% CI: 1.5 to 3.2$)$ or smokeless tobacco $(\mathrm{aOR}=2.7,95 \% \mathrm{CI}$ : 1.5 to 4.7$)$ were each associated with higher odds of initiating P30D cigarette use compared with younger age, identifying as heterosexual/straight and never use of these tobacco products, respectively. Non-Hispanic black $(\mathrm{aOR}=0.6,95 \% \mathrm{CI}$ : 0.4 to 0.9 ) and Hispanic ( $\mathrm{aOR}=0.8,95 \% \mathrm{CI}: 0.6$ to 1.0 ) race/ ethnicity were each associated with lower odds of initiating P30D cigarette use than non-Hispanic white race/ethnicity (table 2).

\section{ENDS}

Among youth, older age $(\mathrm{aOR}=2.4,95 \% \mathrm{CI}: 1.9$ to 3.0$)$, not identifying as heterosexual/straight $(\mathrm{aOR}=1.9,95 \% \mathrm{CI}: 1.3$ to $2.6)$ and ever use of cigarettes $(\mathrm{aOR}=2.9,95 \% \mathrm{CI}: 2.1$ to 4.0$)$, cigars $(\mathrm{aOR}=2.5,95 \% \mathrm{CI}: 1.8$ to 3.5$)$ or hookah $(\mathrm{aOR}=2.6$,
95\% CI: 1.9 to 3.7$)$ were each associated with higher odds of initiating P30D ENDS use compared with younger age, identifying as heterosexual/straight and never use of these tobacco products, respectively. Non-Hispanic black $(\mathrm{aOR}=0.5$, 95\% CI: 0.3 to 0.6$)$, non-Hispanic other $(\mathrm{aOR}=0.6,95 \% \mathrm{CI}$ : 0.4 to 0.8 ) and Hispanic ( $\mathrm{aOR}=0.7,95 \% \mathrm{CI}: 0.5$ to 0.8 ) race/ ethnicity were each associated with lower odds of initiating P30D ENDS use than non-Hispanic white race/ethnicity (table 2).

\section{Cigars}

Among youth, older age $(\mathrm{aOR}=5.7,95 \% \mathrm{CI}$ : 3.9 to 8.3$)$, male sex $(\mathrm{aOR}=2.3,95 \% \mathrm{CI}: 1.7$ to 3.0$)$ and ever use of cigarettes $(\mathrm{aOR}=2.7,95 \% \mathrm{CI}: 1.9$ to 3.7$)$, ENDS $(\mathrm{aOR}=2.4,95 \% \mathrm{CI}: 1.7$ to 3.5$)$, hookah $(\mathrm{aOR}=1.6,95 \% \mathrm{CI}: 1.2$ to 2.3$)$ or smokeless tobacco $(\mathrm{aOR}=1.6,95 \% \mathrm{CI}: 1.1$ to 2.3$)$ were each associated with higher odds of initiating P30D use of cigars compared with younger age, female sex and never use of these tobacco products, respectively (table 2 ).

\section{Hookah}

Among youth, older age $(\mathrm{aOR}=4.1,95 \% \mathrm{CI}: 2.9$ to 5.9$)$, Hispanic ethnicity ( $\mathrm{aOR}=1.5,95 \% \mathrm{CI}: 1.1$ to 2.0$)$ and ever use of ENDS $(\mathrm{aOR}=3.1,95 \% \mathrm{CI}: 2.0$ to 4.7$)$ or cigars $(\mathrm{aOR}=2.3$, 95\% CI: 1.4 to 3.7 ) were each associated with higher odds of initiating P30D hookah use compared with younger age, non-Hispanic white race/ethnicity and never use of ENDS or cigars, respectively (table 2).

\section{Smokeless tobacco}

Among youth, older age ( $\mathrm{aOR}=2.1,95 \% \mathrm{CI}: 1.3$ to 3.3$)$, male sex $(\mathrm{aOR}=4.6,95 \% \mathrm{CI}: 2.7$ to 7.9$)$ and ever use of cigarettes $(\mathrm{aOR}=3.4,95 \% \mathrm{CI}: 2.0$ to 5.8$)$ or $\mathrm{ENDS}(\mathrm{aOR}=2.1,95 \% \mathrm{CI}$ : 1.1 to 3.9) were each associated higher odds of initiating P30D use of smokeless tobacco compared with younger age, female sex and never use of cigarettes or ENDS, respectively. Hispanic ethnicity ( $\mathrm{aOR}=0.4,95 \% \mathrm{CI}: 0.2$ to 0.8 ) was associated with lower odds of initiating P30D smokeless tobacco use compared with non-Hispanic white race/ethnicity (table 2).

\section{Adults}

\section{Any tobacco product}

Among adults, age $25-39(\mathrm{aOR}=0.4,95 \% \mathrm{CI}$ : 0.3 to 0.6$)$ was associated with lower odds of initiating P30D tobacco product use compared with age $18-24$. Male sex $(\mathrm{aOR}=1.5,95 \% \mathrm{CI}$ : 1.0 to 2.3 ) and non-Hispanic black race/ethnicity $(\mathrm{aOR}=1.8$, 95\% CI: 1.2 to 2.7 ) were each associated with higher odds of initiating P30D use compared with female sex or non-Hispanic white race/ethnicity, respectively (table 3 ).

\section{Cigarettes}

Among adults, age $25-39(\mathrm{aOR}=0.6,95 \% \mathrm{CI}: 0.4$ to 0.9$)$ and age $40-54(\mathrm{aOR}=0.1,95 \% \mathrm{CI}: 0.1$ to 0.3$)$ were each associated with lower odds of initiating P30D cigarette smoking compared with age 18-24, and having some college/associate degree $(\mathrm{aOR}=0.5,95 \% \mathrm{CI}: 0.3$ to 0.8$)$ was associated with lower odds of initiating P30D cigarette smoking compared with having less than high school/some high school/GED. Hispanic race/ethnicity $(\mathrm{aOR}=1.8,95 \% \mathrm{CI}: 1.2$ to 2.9$)$, identifying as bisexual $(\mathrm{aOR}=2.4,95 \% \mathrm{CI}: 1.2$ to 4.5$)$ and ever use of ENDS $(\mathrm{aOR}=3.2,95 \% \mathrm{CI}: 2.1$ to 4.9$)$ or cigars $(\mathrm{aOR}=2.1,95 \% \mathrm{CI}: 1.3$ to 3.2) were each associated with higher odds of initiating P30D cigarette smoking compared with non-Hispanic white race/ 


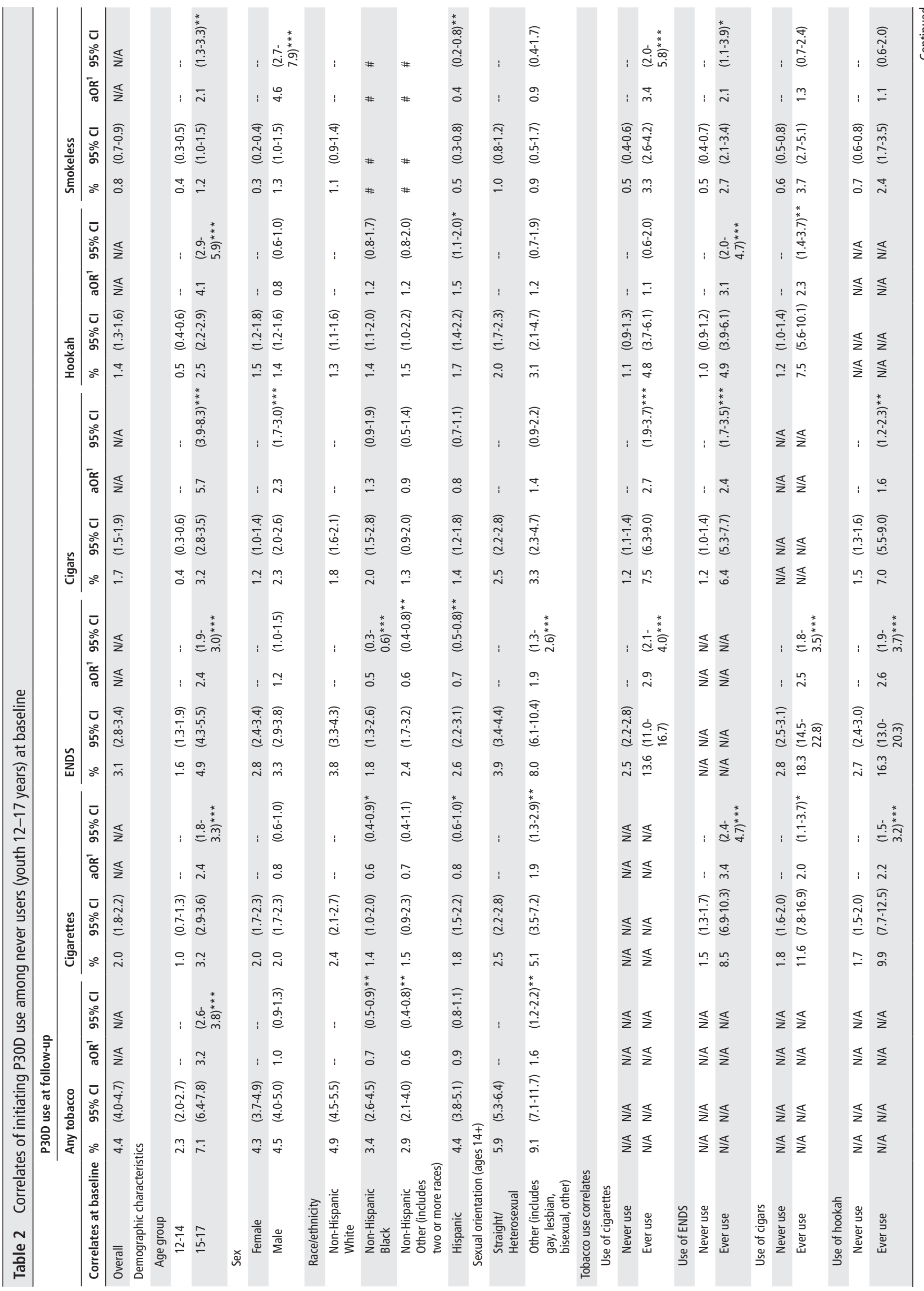




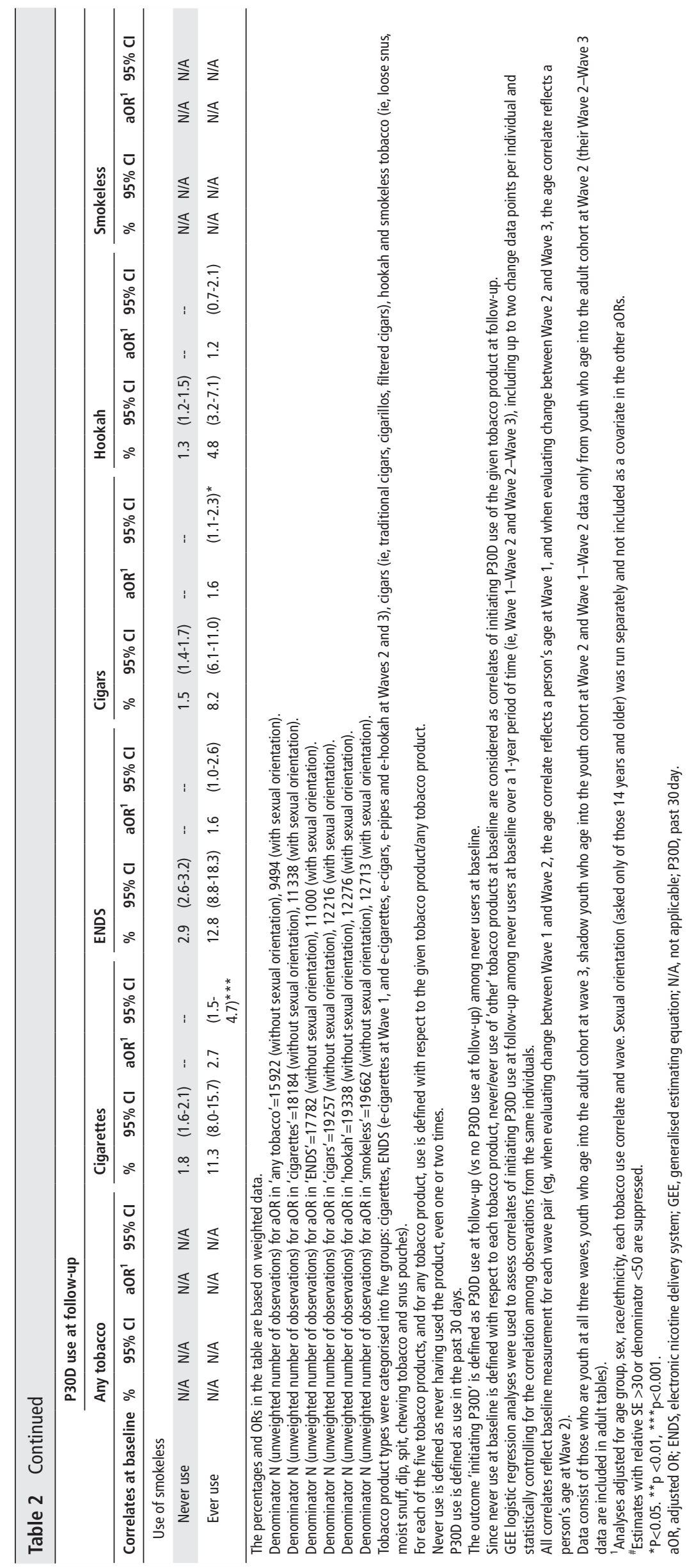




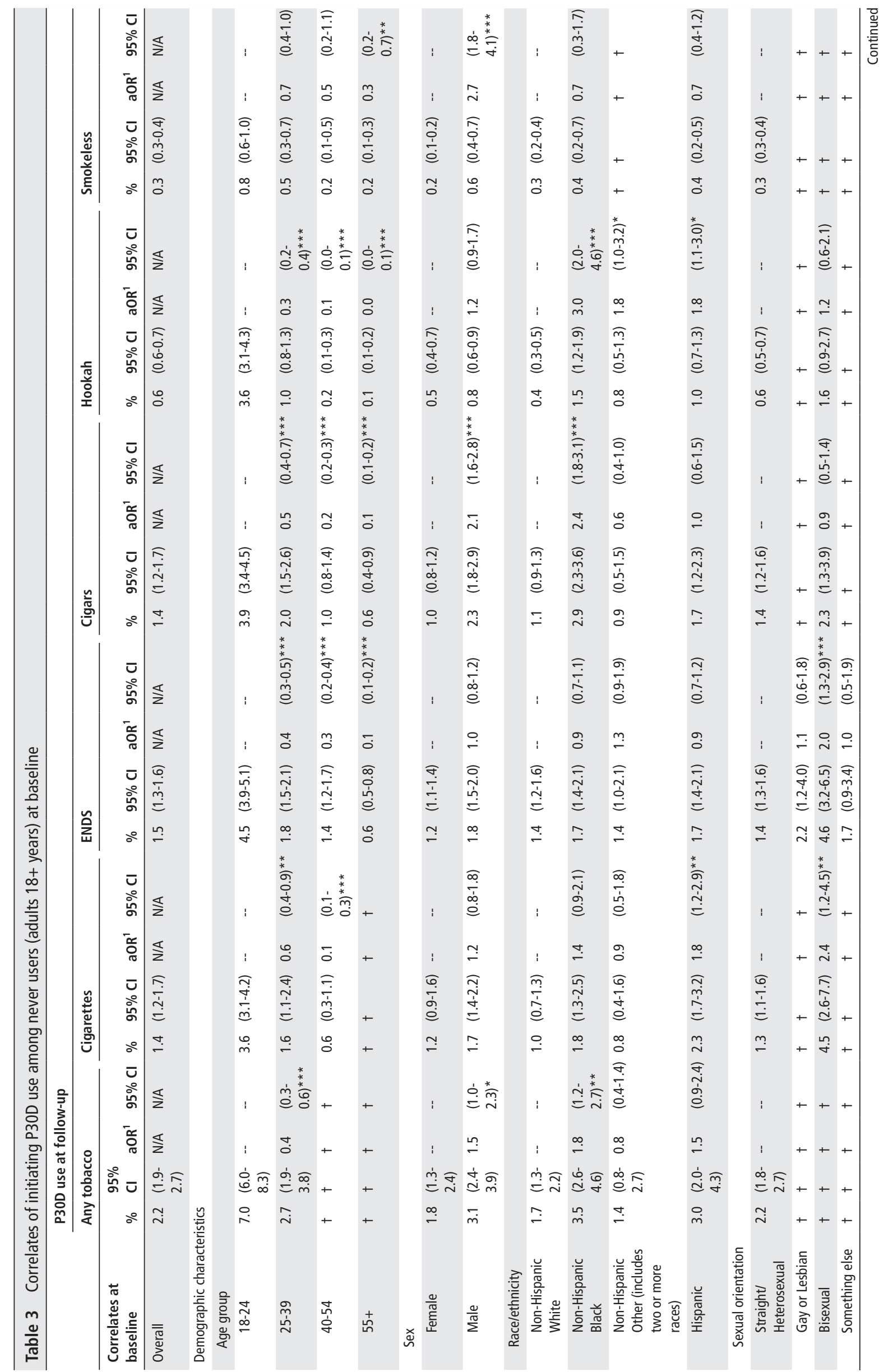




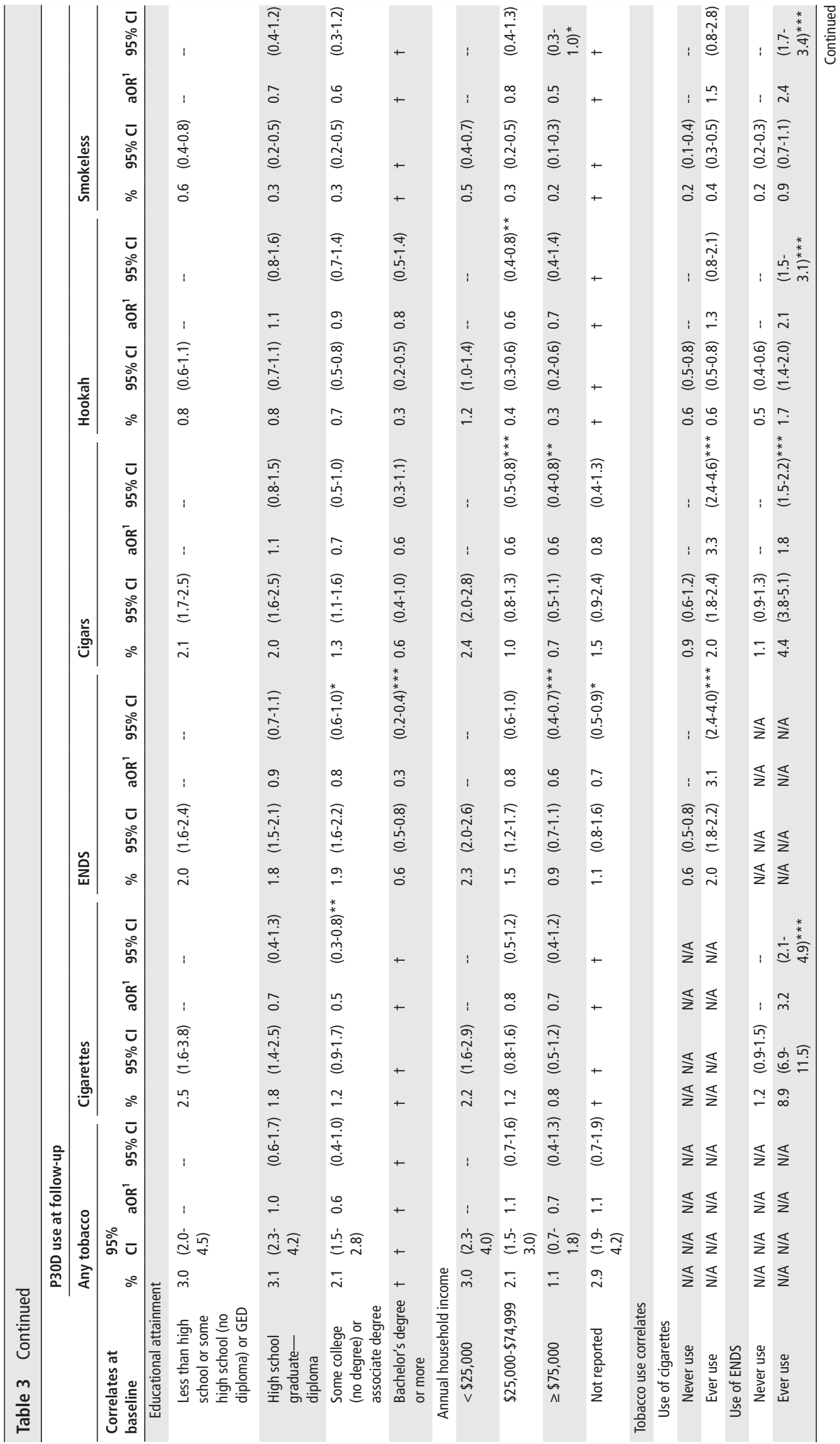




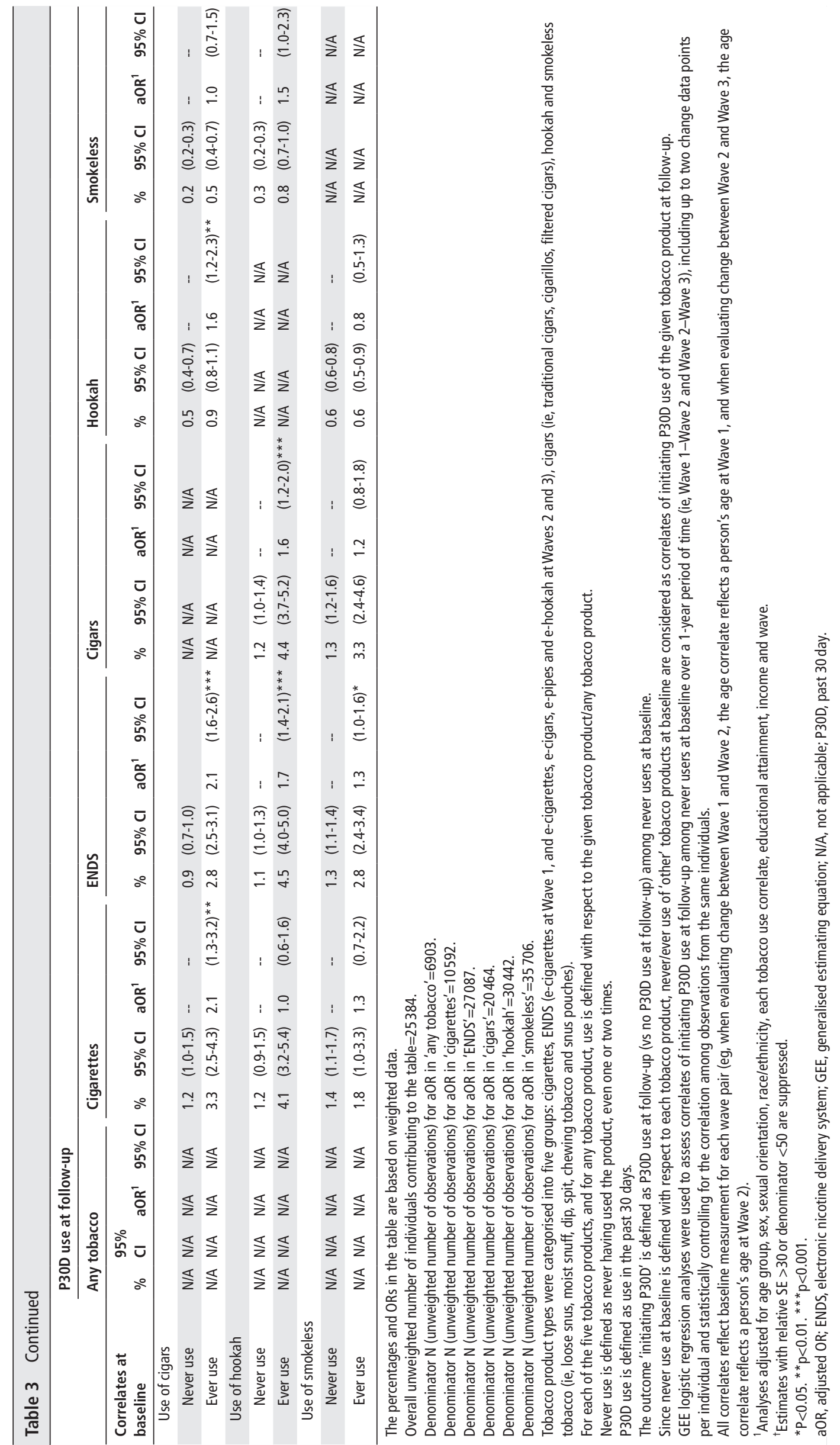


ethnicity, identifying as heterosexual/straight, and never use of ENDS or cigars, respectively (table 3 ).

\section{ENDS}

Among adults, age $25-39(\mathrm{aOR}=0.4,95 \% \mathrm{CI}$ : 0.3 to 0.5$)$, age $40-54(\mathrm{aOR}=0.3,95 \% \mathrm{CI}: 0.2$ to 0.4$)$ and age $55+(\mathrm{aOR}=0.1$, 95\% CI: 0.1 to 0.2 ) were each associated with lower odds of initiating P30D ENDS use compared with age 18-24, having a bachelor's degree or more educational attainment $(\mathrm{aOR}=0.3$, 95\% CI: 0.2 to 0.4 ) or having some college/associate's degree $(\mathrm{aOR}=0.8,95 \% \mathrm{CI}: 0.6$ to 1.0$)$ were each associated with lower odds of initiating P30D ENDS use compared with having less than high school/some high school/GED educational attainment and household income $\geq$ US\$75000 $(\mathrm{aOR}=0.6$, 95\% CI: 0.4 to 0.7 ) was associated with lower odds compared with income $<\mathrm{US} \$ 25000$. Identifying as bisexual $(\mathrm{aOR}=2.0$, $95 \% \mathrm{CI}: 1.3$ to 2.9$)$, and ever use of cigarettes $(\mathrm{aOR}=3.1$, 95\% CI: 2.4 to 4.0$)$, cigars $(\mathrm{aOR}=2.1,95 \% \mathrm{CI}: 1.6$ to 2.6$)$, hookah $(\mathrm{aOR}=1.7,95 \% \mathrm{CI}: 1.4$ to 2.1$)$ or smokeless tobacco $(\mathrm{aOR}=1.3,95 \% \mathrm{CI}: 1.0$ to 1.6$)$ were each associated with higher odds of initiating P30D ENDS use compared with identifying as heterosexual/straight, and never use of these tobacco products, respectively (table 3 ).

\section{Cigars}

Among adults, older age (eg, aOR $=0.1,95 \% \mathrm{CI}: 0.1$ to 0.2 for those aged $55+$ years) and higher household income (eg, $\mathrm{aOR}=0.6,95 \% \mathrm{CI}$ : 0.4 to 0.8 for those with household income $\geq$ US\$75 000) were each associated with lower odds of initiating P30D cigar use compared with age 18-24 years and household income <US\$25 000, respectively. Male sex ( $\mathrm{aOR}=2.1,95 \% \mathrm{CI}: 1.6$ to 2.8$)$, non-Hispanic black race/ ethnicity $(\mathrm{aOR}=2.4,95 \% \mathrm{CI}: 1.8,3.1)$ and ever use of cigarettes $(\mathrm{aOR}=3.3,95 \% \mathrm{CI}: 2.4$ to 4.6$)$, ENDS $(\mathrm{aOR}=1.8$, 95\% CI: 1.5 to 2.2$)$ or hookah $(\mathrm{aOR}=1.6,95 \% \mathrm{CI}: 1.2$ to 2.0) were each associated with higher odds of initiating P30D cigar use compared with female sex, non-Hispanic white race/ ethnicity and never use of these tobacco products, respectively (table 3).

\section{Hookah}

Among adults, older age (eg, aOR $=0.0,95 \% \mathrm{CI}: 0.0$ to 0.1 for those aged 55 + years) and household income US\$25 000US\$74999 (aOR=0.6, 95\% CI: 0.4 to 0.8$)$ were each associated with lower odds of initiating P30D hookah use compared with age 18-24 years and household income <US\$25 000, respectively. Non-Hispanic black race/ethnicity $(\mathrm{aOR}=3.0$, 95\% CI: 2.0 to 4.6 ), Hispanic ethnicity $(\mathrm{aOR}=1.8,95 \% \mathrm{CI}$ : 1.1 to 3.0$)$ and non-Hispanic other race/ethnicity $(\mathrm{aOR}=1.8$, 95\% CI: 1.0 to 3.2 ) were each associated with higher odds of initiating P30D hookah use compared with non-Hispanic white race/ethnicity. Ever use of ENDS ( $\mathrm{aOR}=2.1,95 \% \mathrm{CI}$ : 1.5 to 3.1 ) or cigars ( $\mathrm{aOR}=1.6,95 \% \mathrm{CI}: 1.2$ to 2.3$)$ were each associated with higher odds of initiating P30D hookah use compared with never use of these tobacco products, respectively (table 3 ).

\section{Smokeless tobacco}

Among adults, age 55 years or older $(\mathrm{aOR}=0.3$, 95\% CI: 0.2 to 0.7$)$, and household income $\geq \operatorname{US} \$ 75000(\mathrm{aOR}=0.5$, 95\% CI: 0.3 to 1.0 ) were each associated with lower odds of initiating P30D smokeless tobacco use compared with age 18-24 years household income <US\$25 000, respectively.
Male sex $(\mathrm{aOR}=2.7,95 \% \mathrm{CI}: 1.8$ to 4.1$)$ and ever use of ENDS $(\mathrm{aOR}=2.4,95 \% \mathrm{CI}$ : 1.7 to 3.4$)$ were each associated with higher odds of initiating P30D smokeless tobacco use compared with female sex and never use of ENDS, respectively (table 3 ).

\section{Frequent use on initiation}

We also evaluated rates and correlates of initiating frequent use (use on 20 or more days in the past 30 days) among those who initiated P30D use (hereafter referred to as frequent use on initiation; data shown in-text only).

\section{Youth}

Among youth, 18.6\% (95\% CI: 15.3 to 22.5 ) were frequent users of at least one type of tobacco product on initiation of any tobacco product, with rates of frequent use on initiation by product type as follows: $15.9 \%$ (95\% CI: 12.4 to 20.2 ) for cigarettes, $16.5 \%$ (95\% CI: 13.0 to 20.8 ) for ENDS, $4.4 \%$ (95\% CI: 2.3 to 8.2 ) for cigars, $14.8 \%$ (95\% CI: 9.0 to 23.4 ) for hookah and 29.7\% (95\% CI: 21.0 to 40.1) for smokeless tobacco.

\section{Any tobacco product}

Among youth, age $15-17$ years $(\mathrm{aOR}=1.8,95 \% \mathrm{CI}$ : 1.0 to $3.1)$ and not identifying as heterosexual/straight $(\mathrm{aOR}=3.0$, 95\% CI: 1.3 to 6.8 ) were each associated with higher odds of frequent use on initiation of any tobacco product use compared with age 12-14 years and identifying as heterosexual/straight, respectively.

\section{Cigarettes}

Among youth, Hispanic ethnicity was associated with lower odds of frequent use on initiation of cigarette use $(\mathrm{aOR}=0.4$, 95\% CI: 0.2 to 0.9 ) compared with non-Hispanic white race/ ethnicity.

\section{ENDS}

Among youth, age $15-17$ years $(\mathrm{aOR}=2.3,95 \% \mathrm{CI}$ : 1.1 to 4.6), male sex $(\mathrm{aOR}=2.4,95 \% \mathrm{CI}: 1.2$ to 4.9$)$ and ever use of smokeless tobacco $(\mathrm{aOR}=3.3,95 \% \mathrm{CI}$ : 1.2 to 9.5$)$ were each associated with higher odds of frequent use on initiation of ENDS use compared with age 12-14 years, female sex and never use of ENDS, respectively.

Findings for correlates of frequent use on initiation of cigars, hookah and smokeless tobacco had relative SE $>30 \%$ or were not statistically significant (data not shown).

\section{Adults}

Among adults, 19.2\% (95\% CI: 12.4 to 28.5 ) were frequent users of at least one type of tobacco product on initiation of any tobacco product, with rates of frequent use on initiation by product type as follows: $27.1 \%$ (95\% CI: 18.6 to 37.7$)$ for cigarettes, 24.6\% (95\% CI: 20.9 to 28.6) for ENDS, $20.2 \%$ (95\% CI: 13.7 to 28.8 ) for cigars, $22.0 \%$ (95\% CI: 14.8 to 31.3 ) for hookah and $29.9 \%$ (95\% CI: 21.7 to 39.6) for smokeless tobacco.

\section{ENDS}

Among adults, age 18-24 years $(\mathrm{aOR}=2.8,95 \% \mathrm{CI}: 1.2$ to 6.6$)$ and male sex $(\mathrm{aOR}=1.9,95 \% \mathrm{CI}$ : 1.1 to 3.4$)$ were each associated with higher odds of frequent use on initiation of ENDS use compared with age 55 years or older and female sex, respectively. Non-Hispanic black race/ethnicity 
( $\mathrm{aOR}=0.4,95 \% \mathrm{CI}: 0.2$ to 0.8$)$ and having a bachelor's degree or more educational attainment $(\mathrm{aOR}=0.3,95 \% \mathrm{CI}$ : 0.1 to 0.8 ) were each associated with lower odds of frequent use on initiation of ENDS use compared with non-Hispanic white race/ethnicity and having less than high school/some high school/GED educational attainment, respectively (data not shown).

Findings for correlates of frequent use on initiation of any tobacco product, cigarettes, cigars, hookah and smokeless tobacco had relative SE $>30 \%$ or were not statistically significant (data not shown).

\section{DISCUSSION}

PATH Study W1-W3 data show that, among the US population of youth and adult never users of each type of tobacco product examined here (cigarettes, ENDS, cigars, hookah and smokeless tobacco), age consistently predicted tobacco product initiation, with older youth (aged 15-17 years) more likely than younger youth (aged 12-14 years) and younger adults (aged 18-24 years) more likely than older adults to be P30D tobacco product initiators. Other predictors, however, differed somewhat across types of tobacco products. For example, among youth and adults, males were more likely than females to be P30D cigar and smokeless tobacco use initiators, while among those aged 14-17 years, non-heterosexuals were more likely than heterosexuals to initiate P30D cigarette use and to initiate P30D ENDS use.

Our results also show that for initiation of each type of tobacco product, ever use of another type of tobacco product consistently predicted tobacco product initiation, among both youth and adults. Some studies have found that ENDS use predicts cigarette initiation among youth/young adults. ${ }^{14-17}$ Further, in 2018, the National Academies of Sciences, Engineering, and Medicine published a consensus report Public Health Consequences of E-cigarettes and concluded that there is substantial evidence that ENDS use increases the risk of ever smoking cigarettes among youth and young adults. ${ }^{13}$ Other studies have shown that cigarette smoking predicts ever hookah initiation, ${ }^{29}$ hookah use and snus use each predict ever and P30D cigarette smoking initiation, ${ }^{30}$ and any noncigarette tobacco product use predicts ever cigarette smoking initiation. ${ }^{14}$ Taken together, the association between previous tobacco use and initiation of a new product could be due to common liability and/or shared risk factors ${ }^{31} 32$ such as proclivity to engage in risky behaviours/sensation-seeking, ${ }^{33}$ receptivity/susceptibility to use tobacco, ${ }^{34} 35$ having friends who use tobacco, ${ }^{36}$ other substance use ${ }^{37}$ or household exposure to tobacco, ${ }^{38}$ which were not examined in this study. Findings could also be due to nicotine dependence since all tobacco products contain the addictive substance, although perhaps in different amounts. ${ }^{39}$ Additionally, change in social group, ${ }^{40}$ normalisation of tobacco use $\mathrm{u}^{41}$ and experience in/becoming accustomed to using one type of tobacco product may relate to initiating use of another type of tobacco product. ${ }^{42}$ Future studies can examine individual-level, family-level, societallevel and policy-related factors implicated in tobacco use initiation, which may also be related to our observed associations with demographic characteristics.

Our findings also identify a difference in correlates of P30D initiation versus correlates of frequent use on initiation. Adults aged 55 years or older were far less likely than young adults to be P30D ENDS initiators but were nearly three times more likely than young adults to be frequent ENDS users on initiation. Coupled with the findings that cigarette use predicts ENDS initiation and that, among adult cigarette smokers, those who use ENDS are more likely to attempt to quit than those who do not use ENDS, ${ }^{43}$ demographic differences in frequency of use on initiation may be explained by differences in reasons for product use. Several studies have found that adult cigarette smokers use ENDS to assist them in quitting smoking cigarettes ${ }^{44}$ or for use in places where smoking is not allowed, ${ }^{46}$ with young adults being more likely than older adults to report use because of flavourings. ${ }^{47}$ Differences between young adults and older adults in their reasons for ENDS use ${ }^{48}$ may help to explain differences in patterns of use.

\section{Limitations}

The findings reported here importantly cover individuallevel correlates of tobacco product initiation across a range of tobacco products, although we grouped different types of ENDS and different types of cigars together. We also did not examine many psychosocial and other factors that may be important to tobacco product initiation. Furthermore, ENDS have evolved since their introduction to the marketplace, ${ }^{49}$ with newer generation 'pod-mod' ENDS having risen in popularity after the time that these data were collected. ${ }^{50}$

\section{Summary and implications}

This study uses nationally representative longitudinal data from youth and adults to evaluate correlates of ever, P30D and more frequent tobacco product use initiation. Demographic correlates of initiation underscore tobacco use disparities in the USA, and tobacco use correlates suggest that use of another tobacco product is a common risk factor for initiation across products. Taken together with the rest of the data reported in this issue, findings can be used to better tailor prevention and cessation interventions, and can lay the foundation for subsequent work and enable researchers to strengthen populationlevel predictions of the potential impacts of regulatory actions and other interventions on tobacco product use.

What this paper adds

Previous research that is focused on ever tobacco use initiation may be missing important correlates of tobacco product use initiation related to negative health outcomes due to more consistent use.

- This study uses nationally representative longitudinal data from youth and adults to evaluate correlates of past 30-day (P30D) use initiation and more frequent use initiation across multiple tobacco products.

- Ever use of another type of tobacco product consistently predicted tobacco product initiation, among both youth and adults, whereas demographic correlates showed more product-specific findings, consistent with previous literature.

- Our findings also identify some differences in correlates of P30D initiation versus correlates of frequent use on initiation.

- Adults aged 55 years or older were far less likely than young adults to be P30D ENDS initiators but were nearly three times more likely than young adults to be frequent ENDS users on initiation.

- Demographic correlates of P30D initiation underscore tobacco use disparities in the USA, and tobacco use correlates of initiation suggest that use of another tobacco product is a common risk factor for initiation across products. 
Contributors KAK and KCE led the conceptual design of the work. KAK drafted the initial manuscript and all authors critically revised it. ZT conducted the statistical analyses and all authors contributed to the interpretation of results. All authors approved the work for journal publication and agreed to be accountable for all aspects of the work.

Funding This study is supported by Federal funds from the National Institute on Drug Abuse, National Institutes of Health and the Center for Tobacco Products, Food and Drug Administration, Department of Health and Human Services, under a contract to Westat (Contract No. HHSN271201100027C).

Disclaimer The findings and conclusions in this report are those of the authors and do not necessarily represent the official position of the US Department of Health and Human Services or any of its affiliated institutions or agencies.

Competing interests WMC reports long-term stock holdings in General Electric Company, 3M Company, and Pfizer Incorporated, unrelated to this manuscript. No financial disclosures were reported by the other authors of this paper.

Patient consent for publication Not required.

Ethics approval The study was conducted by Westat and approved by the Westat Institutional Review Board. All respondents ages 18 and older provided informed consent, with youth respondents ages 12 to 17 providing assent and each youth's parent/legal guardian providing consent.

Provenance and peer review Not commissioned; internally peer reviewed.

Data availability statement Data from the PATH Study Wave 1 to Wave 3 may be obtained from a third party and are not publicly available (https://www. icpsr.umich.edu/icpsrweb/NAHDAP/studies/36231). Applications instructions and conditions of use are available at the website above.

\section{ORCID iDs}

Karin A Kasza http://orcid.org/0000-0002-4492-098X

Kathryn C Edwards http://orcid.org/0000-0002-0645-1705

Cassandra A Stanton http://orcid.org/0000-0001-5329-6261

Eva Sharma http://orcid.org/0000-0002-1328-508X

Michael J Halenar http://orcid.org/0000-0002-8703-3811

Kristie A Taylor http://orcid.org/0000-0001-6668-7923

Maansi Bansal-Travers http://orcid.org/0000-0002-7944-3570

Lisa D Gardner http://orcid.org/0000-0003-3340-2818

Heather L Kimmel http://orcid.org/0000-0001-8278-0095

\section{REFERENCES}

1 Hyland A, Kasza KA, Borek N, et al. Overview of tobacco use transitions for population health. Tob Control 2020;29:s134-8.

2 U.S. Department of Health and Human Services. Preventing Tobacco Use Among Youth and Young Adults: A Report of the Surgeon General. Atlanta, GA: U.S. Department of Health and Human Services, Centers for Disease Control and Prevention, National Center for Chronic Disease Prevention and Health Promotion, Office on Smoking and Health, 2012.

3 Stanton CA, Sharma E, et al. Initiation of any tobacco and five tobacco products across three years among youth, young adults, and adults in the USA: findings from the PATH Study Waves 1-3 (2013-2016). Tob Control 2020;29:s178-90.

4 Kasza KA, Ambrose BK, Conway KP, et al. Tobacco-Product use by adults and youths in the United States in 2013 and 2014. N Eng/ J Med 2017;376:342-53.

5 Gerend MA, Newcomb ME, Mustanski B. Prevalence and correlates of smoking and e-cigarette use among young men who have sex with men and transgender women. Drug Alcohol Depend 2017;179:395-9.

6 Trapl ES, Yoder LD, Frank JL, et al. Individual, parental, and environmental correlates of cigar, cigarillo, and little cigar use among middle school adolescents. Nicotine Tob Res 2016;18:834-41.

7 Agaku IT, King BA, Husten CG, et al. Tobacco product use among adults--United States, 2012-2013. MMWR Morb Mortal Wkly Rep 2014;63:542-7.

8 Shaikh RA, Siahpush M, Singh GK, et al. Socioeconomic, demographic and smokingrelated correlates of the use of potentially reduced exposure to tobacco products in a national sample. Tob Control 2014;23:353-8.

9 Wheldon CW, Kaufman AR, Kasza KA, et al. Tobacco use among adults by sexual orientation: findings from the population assessment of tobacco and health study. LGBT Health 2018;5:33-44.

10 Rath JM, Villanti AC, Rubenstein RA, et al. Tobacco use by sexual identity among young adults in the United States. Nicotine Tob Res 2013;15:1822-31.

11 Lee YO, Hebert CJ, Nonnemaker JM, et al. Multiple tobacco product use among adults in the United States: cigarettes, cigars, electronic cigarettes, hookah, smokeless tobacco, and snus. Prev Med 2014;62:14-19.

12 Rath JM, Villanti AC, Abrams DB, et al. Patterns of tobacco use and dual use in US young adults: the missing link between youth prevention and adult cessation. $J$ Environ Public Health 2012;2012:1-9.

13 National Academies of Sciences Engineering and Medicine. Public health consequences of e-cigarettes. Washington, DC: The National Academies Press, 2018.
14 Watkins SL, Glantz SA, Chaffee BW. Association of Noncigarette tobacco product use with future cigarette smoking among youth in the population assessment of tobacco and health (path) study, 2013-2015. JAMA Pediatr 2018;172:181-7.

15 Loukas A, Marti CN, Cooper M, et al. Exclusive e-cigarette use predicts cigarette initiation among college students. Addict Behav 2018;76:343-7.

16 Chaffee BW, Couch ET, Gansky SA. Trends in characteristics and multi-product use among adolescents who use electronic cigarettes, United States 2011-2015. PLoS One 2017;12:e0177073.

17 Leventhal AM, Strong DR, Kirkpatrick MG, et al. Association of electronic cigarette use with initiation of combustible tobacco product smoking in early adolescence. JAMA 2015;314:700-7

18 Berry KM, Fetterman JL, Benjamin EJ, et al. Association of electronic cigarette use with subsequent initiation of tobacco cigarettes in US youths. JAMA Netw Open 2019;2:e187794.

19 Wellmann KF. [Smoking and health. on the report of the advisory committee to the surgeon general of the public health service]. Dtsch Med Wochenschr 1964;89:1085-6.

20 Hyland A, Ambrose BK, Conway KP, et al. Design and methods of the Population Assessment of Tobacco and Health (PATH) Study. Tob Control 2017;26:371-8.

21 Population Assessment of Tobacco and Health (PATH) Study. Available: https://doi.org/ 10.3886/Series606

22 United States Public Health Service. Preventing tobacco use among young people: A report of the Surgeon General. US Department of Health and Human Services, Centers for Disease Control and Prevention 1994.

23 Kann L, Brener ND, Warren CW, et al. An assessment of the effect of data collection setting on the prevalence of health risk behaviors among adolescents. J Adolesc Health 2002;31:327-35.

24 PATH Study Restricted Use Files. Available: https://www.icpsr.umich.edu/icpsrweb/ NAHDAP/studies/36231

25 Liang K-YEE, Zeger SL. Longitudinal data analysis using generalized linear models. Biometrika 1986;73:13-22.

26 Hardin JW, Hilbe JM. Generalized estimating equations. Boca Raton, FL: Chapman and Hall/CRC, 2003.

27 McCarthy PJ. Pseudoreplication: further evaluation and applications of the balanced half-sample technique. Vital Health Stat 2 1969;31:1-24.

28 Judkins DR. Fay's method for variance estimation. Journal of Official Statistics 1990;6:223.

29 Villanti AC, Cobb CO, Cohn AM, et al. Correlates of hookah use and predictors of hookah trial in U.S. young adults. Am J Prev Med 2015;48:742-6.

30 Soneji S, Sargent JD, Tanski SE, et al. Associations between initial water pipe tobacco smoking and snus use and subsequent cigarette smoking: results from a longitudinal study of US adolescents and young adults. JAMA Pediatr 2015;169:129-36.

31 Jessor R. Risk behavior in adolescence: a psychosocial framework for understanding and action. J Adolesc Health 1991;12:597-605.

32 Vanyukov MM, Tarter RE, Kirillova GP, et al. Common liability to addiction and "gateway hypothesis": theoretical, empirical and evolutionary perspective. Drug Alcohol Depend 2012;123 Suppl 1:S3-17.

33 Colder CR, Scalco M, Trucco EM, et al. Prospective associations of internalizing and externalizing problems and their co-occurrence with early adolescent substance use. J Abnorm Child Psychol 2013;41:667-77.

34 Pierce JP, Sargent JD, White MM, et al. Receptivity to tobacco advertising and susceptibility to tobacco products. Pediatrics 2017;139:e20163353.

35 Trinidad DR, Pierce JP, Sargent JD, et al. Susceptibility to tobacco product use among youth in Wave 1 of the Population Assessment of Tobacco and Health (PATH) Study. Prev Med 2017:101:8-14.

36 Strong DR, Messer K, Hartman SJ, et al. Pre-adolescent receptivity to tobacco marketing and its relationship to acquiring friends who smoke and cigarette smoking initiation. Ann Behav Med 2017;51:730-40.

37 Silveira ML, Conway KP, Green VR, et al. Longitudinal associations between youth tobacco and substance use in Waves 1 and 2 of the Population Assessment of Tobacco and Health (PATH) Study. Drug Alcohol Depend 2018;191:25-36.

38 Wakefield MA, Chaloupka FJ, Kaufman NJ, et al. Effect of restrictions on smoking at home, at school, and in public places on teenage smoking: cross sectional study. BMJ 2000;321:333-7.

39 Djordjevic MV, Doran KA. Nicotine Content and Delivery Across Tobacco Products. In: Henningfield JE, London ED, Pogun S, eds. Nicotine psychopharmacology. Handbook of experimental pharmacology. 192. Springer, Berlin, Heidelberg, 2009.

40 Schneider S, Diehl K. Vaping as a catalyst for smoking? an initial model on the initiation of electronic cigarette use and the transition to tobacco smoking among adolescents. Nicotine Tob Res 2016;18:647-53.

41 Wills TA, Knight R, Williams RJ, et al. Risk factors for exclusive e-cigarette use and dual e-cigarette use and tobacco use in adolescents. Pediatrics 2015;135:e43-51.

42 Brandon TH, Herzog TA, Irvin JE, et al. Cognitive and social learning models of drug dependence: implications for the assessment of tobacco dependence in adolescents. Addiction 2004;99 Suppl 1:51-77.

43 Kasza KA, Tang Z. Correlates of tobacco product cessation among youth and adults in the USA: findings from the PATH Study Waves 1-3 (2013-2016). Tob Control 2020;29:s203-15. 
44 Delnevo CD, Giovenco DP, Steinberg MB, et al. Patterns of electronic cigarette use among adults in the United States. Nicotine Tob Res 2016;18:715-9.

45 Richardson A, Pearson J, Xiao H, et al. Prevalence, harm perceptions, and reasons for using noncombustible tobacco products among current and former smokers. Am J Public Health 2014;104:1437-44.

46 Coleman BN, Rostron B, Johnson SE, et al. Electronic cigarette use among US adults in the Population Assessment of Tobacco and Health (PATH) Study, 2013-2014. Tob Control 2017;26:e117-26.
47 Patel D, Davis KC, Cox S, et al. Reasons for current e-cigarette use among U.S. adults. Prev Med 2016;93:14-20.

48 Chapman SL, Wu L-T. E-Cigarette prevalence and correlates of use among adolescents versus adults: a review and comparison. J Psychiatr Res 2014;54:43-54.

49 Etter J-F. Characteristics of users and usage of different types of electronic cigarettes: findings from an online survey. Addiction 2016;111:724-33.

50 Barrington-Trimis JL, Leventhal AM. Adolescents' Use of "Pod Mod" E-Cigarettes Urgent Concerns. N Engl J Med 2018;379:1099-102. 